\title{
Googling for Ticks and Borreliosis in Germany: Nationwide Google Search Analysis From 2015 to 2018
}

Cora Scheerer, MD; Melvin Rüth; Linda Tizek, MPH, PhD; Martin Köberle, PhD; Tilo Biedermann, Prof Dr, MD; Alexander Zink, MD, MPH, PhD

Department of Dermatology and Allergy, Technical University of Munich, Munich, Germany

Corresponding Author:

Alexander Zink, MD, MPH, PhD

Department of Dermatology and Allergy

Technical University of Munich

Biedersteinerstr.29

Munich, 80802

Germany

Phone: 4908941400

Email: alexander.zink@tum.de

\section{Abstract}

Background: Borreliosis is the most frequently transmitted tick-borne disease in Europe. It is difficult to estimate the incidence of tick bites and associated diseases in the German population due to the lack of an obligation to register across all 16 federal states of Germany.

Objective: The aim of this study is to show that Google data can be used to generate general trends of infectious diseases on the basis of borreliosis and tick bites. In addition, the possibility of using Google AdWord data to estimate incidences of infectious diseases, where there is inconsistency in the obligation to notify authorities, is investigated with the perspective to facilitate public health studies.

Methods: Google AdWords Keyword Planner was used to identify search terms related to ticks and borreliosis in Germany from January 2015 to December 2018. The search volume data from the identified search terms was assessed using Excel version 15.23. In addition, SPSS version 24.0 was used to calculate the correlation between search volumes, registered cases, and temperature.

Results: A total of 1999 tick-related and 542 borreliosis-related search terms were identified, with a total of 209,679,640 Google searches in all 16 German federal states in the period under review. The analysis showed a high correlation between temperature and borreliosis $(r=0.88)$, and temperature and tick bite $(r=0.83)$, and a very high correlation between borreliosis and tick bite $(r=0.94)$. Furthermore, a high to very high correlation between Google searches and registered cases in each federal state was observed (Brandenburg $r=0.80$, Mecklenburg-West Pomerania $r=0.77$, Saxony $r=0.74$, and Saxony-Anhalt $r=0.90$; all $P<.001$ ).

Conclusions: Our study provides insight into annual trends concerning interest in ticks and borreliosis that are relevant to the German population exemplary in the data of a large internet search engine. Public health studies collecting incidence data may benefit from the results indicating a significant correlation between internet search data and incidences of infectious diseases.

(J Med Internet Res 2020;22(10):e18581) doi: $\underline{10.2196 / 18581}$

\section{KEYWORDS}

Google; infodemiology; infoveillance; public health; seasonal health trend; medical internet research; tick-borne disease; tick bites, borreliosis; Lyme disease

\section{Introduction}

Borreliosis is the most frequently transmitted tick-borne disease in Europe. In $80 \%-90 \%$ of all cases, the disease presents with visible skin manifestations [1-3]. However, there is limited accurate data for the incidence of tick bites and borreliosis as associated diseases in Germany. Tick bites and associated diseases are important public health concerns because of their high incidence with no clear increasing or decreasing trend in Germany with regional variation [4]. Tick bite protection, correct and prompt tick removal, and medical consultation should be promoted by physicians and health authorities to facilitate early diagnosis and treatment of associated diseases. 
In 9 out of 16 federal states in Germany (Bavaria, Berlin, Brandenburg, Mecklenburg-West Pomerania, Rhineland-Palatinate, Saarland, Saxony, Saxony-Anhalt, and Thuringia), it is mandatory to report diagnosed borreliosis to the German federal government agency and research institute for disease control and prevention (Robert-Koch Institute). Thus, epidemiologic data for tick bites and associated diseases are based on measured, as well as estimated, values.

Google search analysis is a powerful tool to reflect the German population's interest in specific topics because of its $94 \%$ market share [5]. Additionally, the general public favors search engines like Google over specialized websites when searching for primary health information online [6-9]. Previous studies have already demonstrated that analysis of internet search volume, which is one of the methods of the fields of infodemiology and infoveillance, is a valid method for assessing medical topics [10-15]. The internet's emerging role as a main, or at least primary, source of health advice for the general public has prompted a corresponding increase in its value in the medical field. Huang et al [16], for example, reported a minor association between online cancer-related information searches and skin cancer incidence. Additionally, Wehner et al [17] established that internet search volume positively correlates with the incidence and mortality rates of common cancers in the United States. Regarding infectious diseases, Ginsberg et al [18] showed an accurate estimation of weekly influenza activity in the United States correlated with queries in online search engines. They suggested that internet research could help physicians diagnose influenza earlier to prevent epidemics [18].

Ticks are only active when ambient air temperature is $4-10^{\circ} \mathrm{C}$, so average temperature should be an important factor influencing tick-related queries. Therefore, weather data should provide insight into seasonal patterns [19]. Previous studies have shown that there are seasonal patterns in Google search volumes but have not found significant correlation between mean monthly temperature and internet searches for "tick" [20].

This study aims to investigate the interest of the German population in tick bites and borreliosis by analyzing Google searches. Furthermore, this study aims to explore correlations between searches and whether that could provide information about real life tick bite occurrences, as well as associated diseases.

\section{Methods}

\section{Study Design}

In this retrospective study, Google AdWords Keyword Planner was used to measure the search volume of terms related to tick bites and borreliosis across Germany from January 2015 to December 2018. The Keyword Planner is often used by advertisers to improve Google marketing campaigns and provides monthly search volumes estimated by Google. The term search volume applies to the number of searches for a topic or search term. To assess search volume within a specific field, words are initially entered into the Keyword Planner; thereupon, the program provides keywords that are most relevant to the topic. This process may be used both to answer scientific questions and for medical research [10,11].

In addition, search terms related to tick bites were identified using a keyword cluster for the German words for "tick bite" ("Zeckenbiss") and "borreliosis" ("Borreliose"). Based on this cluster, Google AdWords Keyword Planner determined search terms to be analyzed. This data included only Google users with a German internet protocol address who used the German language. Furthermore, the German Climate Data Centre [21] was used to relate Google search volume to weather data by analyzing mean monthly temperature in degrees Celsius. Due to seasonal differences in tick activity as well as tick bite incidence, we defined summer months as April to September and winter months as October to March.

In 9 of 16 federal states in Germany (Bavaria, Berlin, Brandenburg, Mecklenburg-West Pomerania, Rhineland-Palatinate, Saarland, Saxony, Saxony-Anhalt, and Thuringia) covering $42 \%$ of the total German population, mandatory notification for the three most common Lyme borreliosis manifestations (erythema migrans, acute neuroborreliosis, and Lyme arthritis) has been achieved since 2013.

To assess whether the Google search volume correlates with registered cases of borreliosis, all registered cases from the federal states of Brandenburg, Mecklenburg-West Pomerania, Saxony, and Saxony-Anhalt were considered in the analysis, as complete statistics of registered data were only available for these on the website of the German federal government agency and research institute for disease control and prevention (Robert-Koch Institut).

\section{Statistical Analysis}

The search volume data of the identified search terms was assessed using Excel version 15.23 (Microsoft Corporation). To describe the relationship between the investigated variables, we used SPSS version 24.0 (IBM Corp) to calculate the Pearson correlation coefficient $(r)$ [22].

\section{Results}

In total, Google AdWords Keyword Planner identified 1999 search terms related to tick bites with a search volume of 26,080,530 in Germany from January 2015 to December 2018. The most frequently searched terms were "tick sting" ("Zeckenstich"; n=2,821,800, 10.82\%), "tick" ("Zecke"; $\mathrm{n}=2,387,500,9.15 \%$ ), and "tick bite" ("Zeckenbiss"; $\mathrm{n}=178,850$, $0.69 \%$; Textbox 1). 
Textbox 1. Top five key terms for tick bite (Zeckenbiss) and borreliosis (Borreliose).

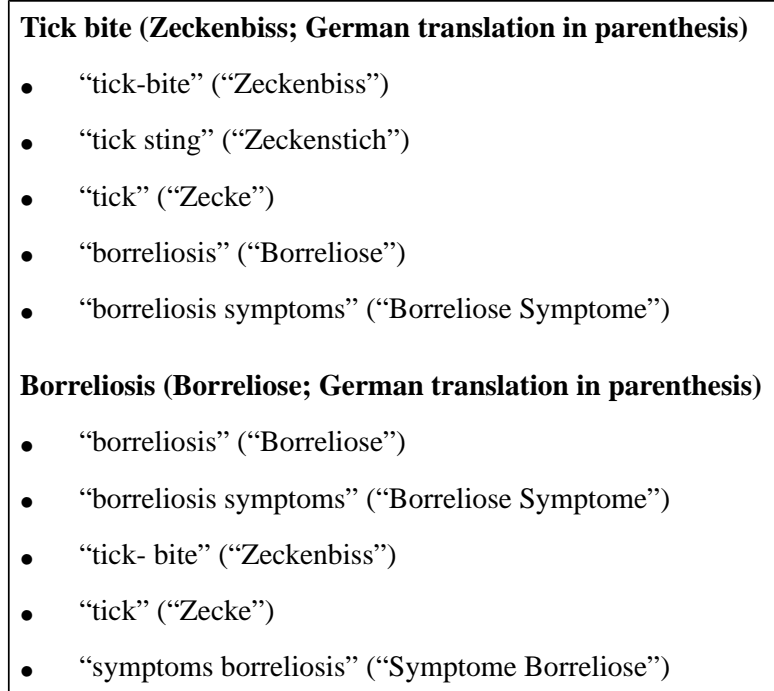

Every year, an increase in search volume during summer months was observed (Figure 1). The month with the highest overall search volume was June 2018 with 1,571,330 searches. The search volume of tick bite and borreliosis showed similar trends in search volume, with "borreliosis" being more frequently searched. Annual peaks of search volume for tick bite were seen every year in June. Annual peaks of search volume for borreliosis happened in June and July of 2015 and 2016 ( $n=201,000$ searches each), July 2017 ( $n=246,000$ searches), and June and July 2018 (n=246,000 searches each; Figure 2).

Figure 1. Google searches in Germany in summer (April to September) vs winter months (October to March) for the top five tick- and borreliosis-related search terms in 2015-2018.

\section{Sum of Google searches in summer versus winter for top 3000000 five "tick" and "borreliosis" related search terms}

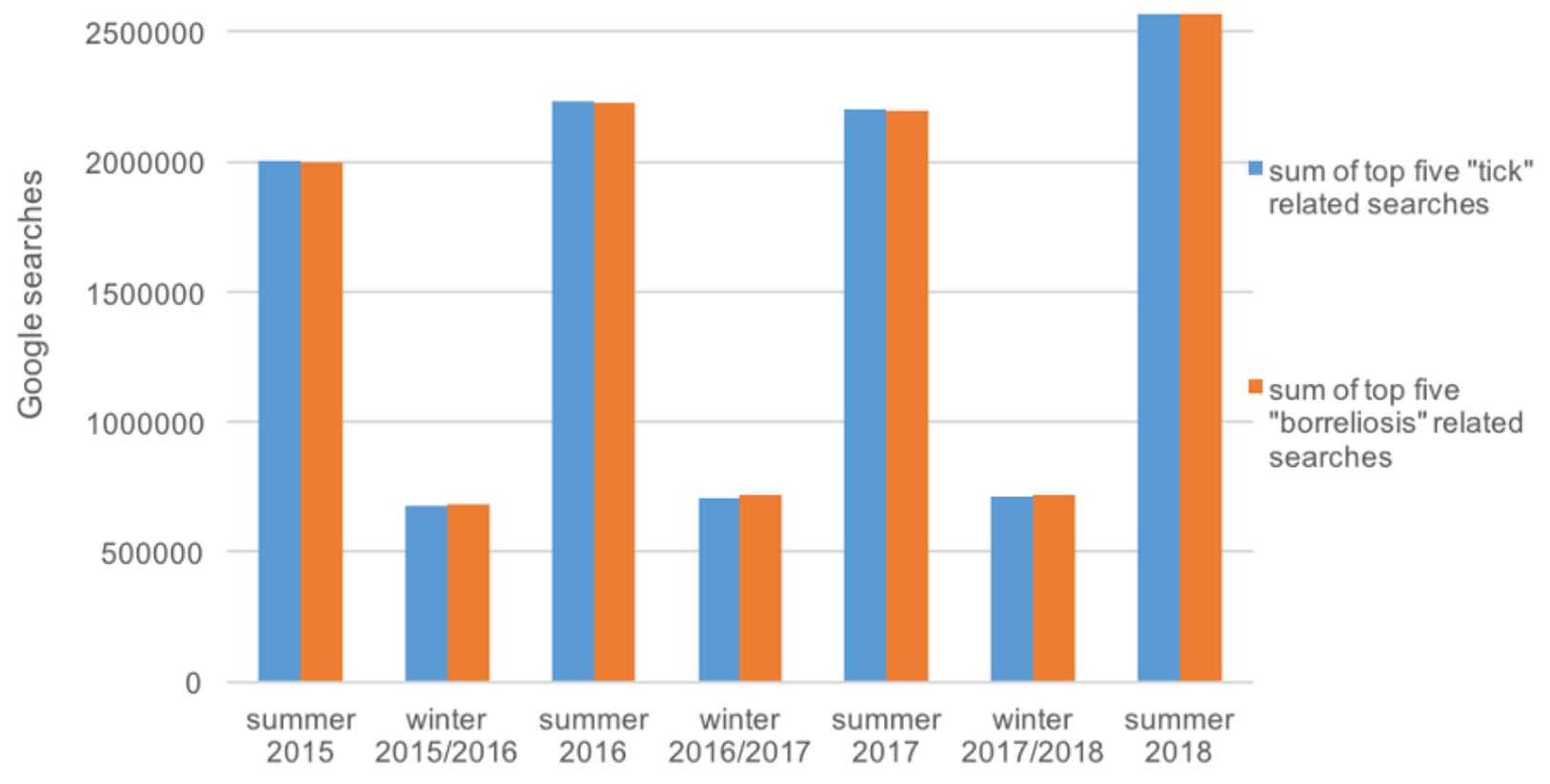


Figure 2. Seasonal variation of the two most common keywords searched for in Germany, "tick-bite" and "borreliosis," from January 2015 to December 2018.

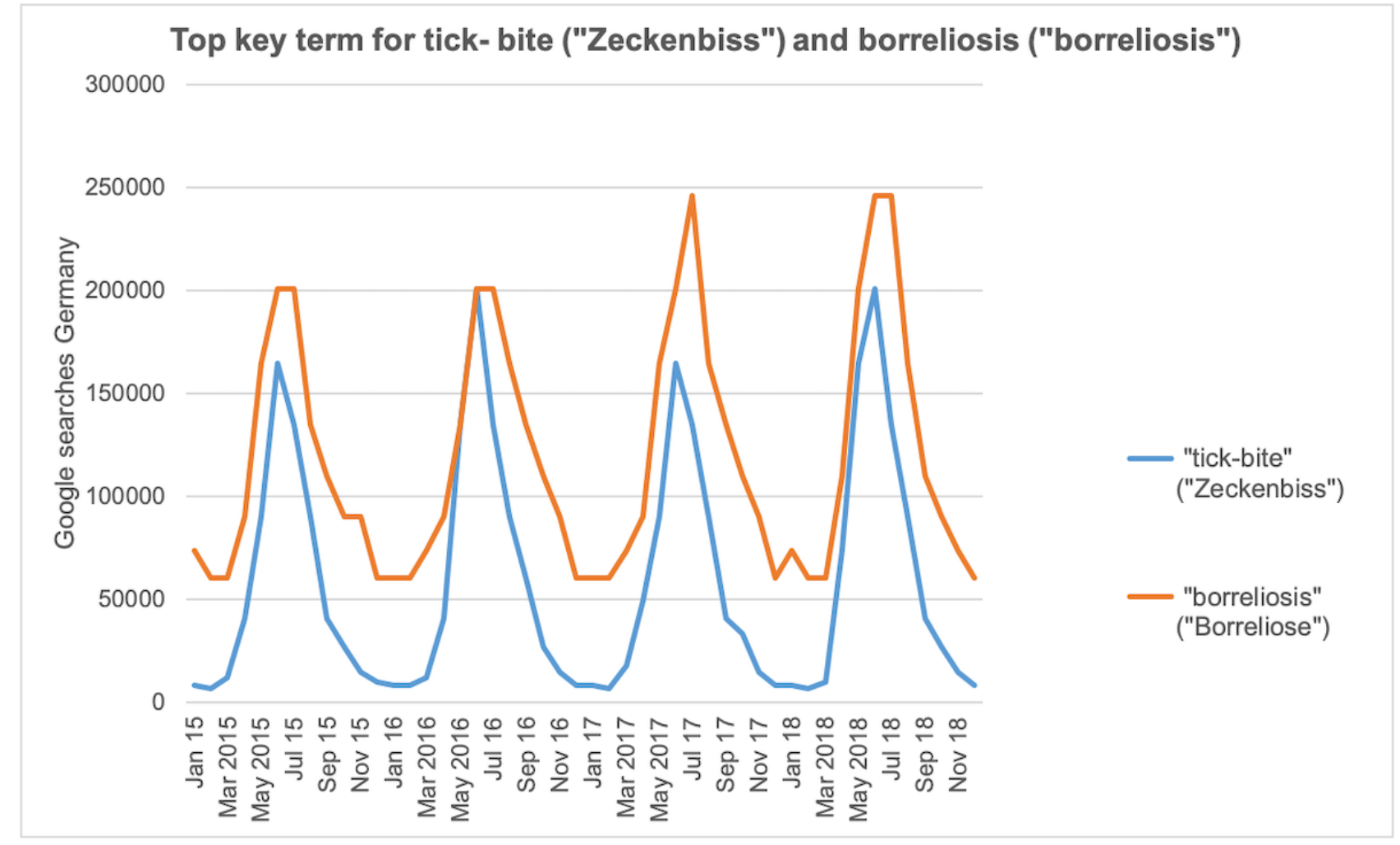

The analysis revealed a high correlation between temperature and borreliosis $(r=0.88, P<.001)$ as well as between temperature and tick bite $(r=0.83, P<.001$; Figure 3$)$. The very high correlation between borreliosis and tick bite $(r=0.94, P<.001)$ depicts the seasonal- and temperature-dependent interest in the key terms.

Figure 3. Google searches in Germany for "tick bite" and "borreliosis" correlated with the monthly average temperature in Germany in Celsius degrees between January 2015 to December 2018.

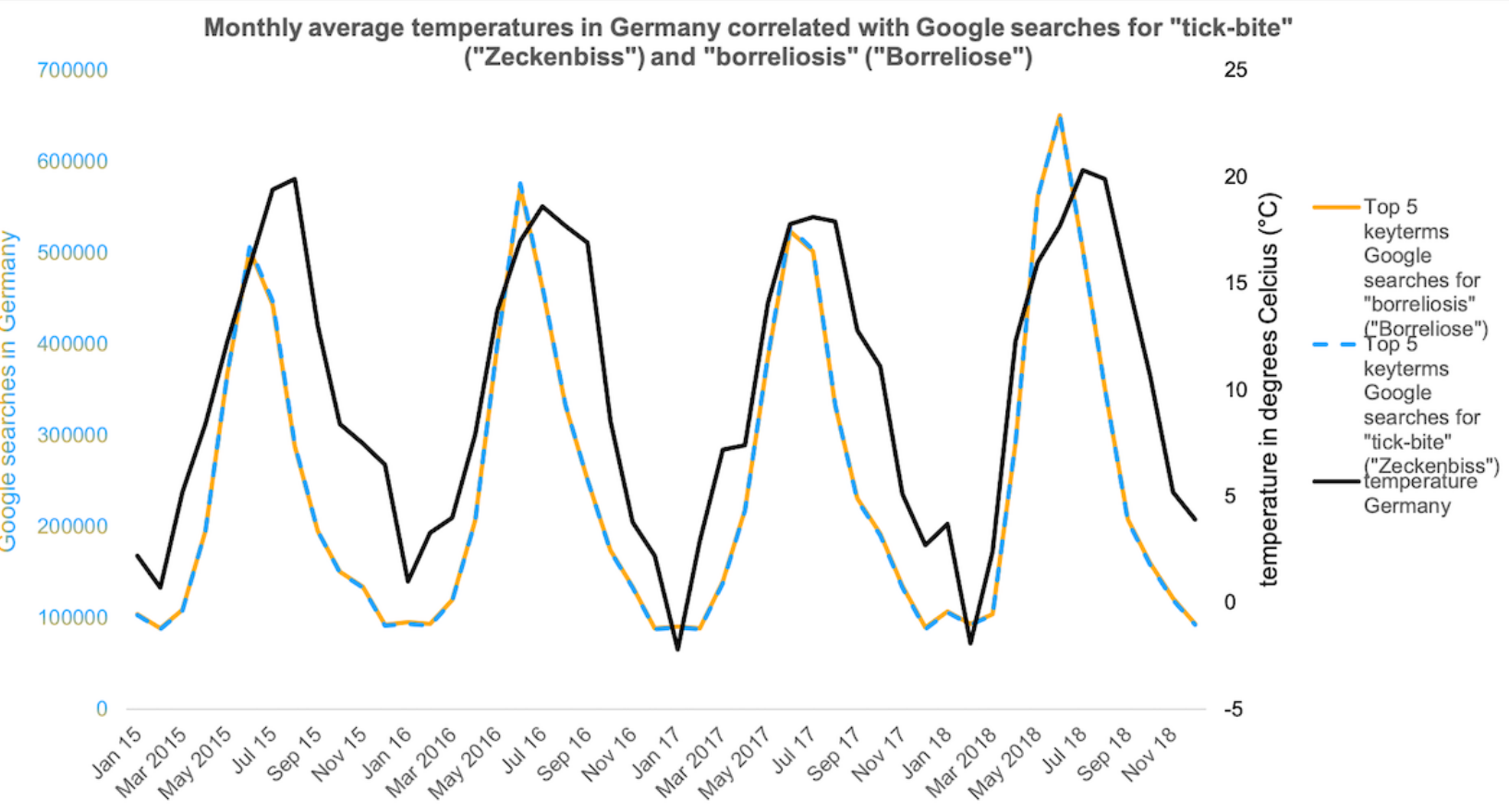

Furthermore, a high and very high correlation between google searches and registered cases in the referred federal states Brandenburg, Mecklenburg-West Pomerania, Saxony, and Saxony-Anhalt were detected (Figure 4; Table 1). Saxony, the federal state with the largest population, had the highest number of Google searches ( $n=273,800$ searches), as well as the highest number of registered cases of borreliosis $(\mathrm{n}=7387)$. Accordingly, a high correlation was found $(r=0.74, P<.001)$. However, the 
highest correlation was found in Saxony-Anhalt ( $r=0.90, \quad P<.001$; Table 1 and Figure 4).

Figure 4. Number of Google searches for "borreliosis" with registered cases of borreliosis in Brandenburg, Mecklenburg-West Pomerania, Saxony, and Saxony-Anhalt between January 2015 to December 2018.
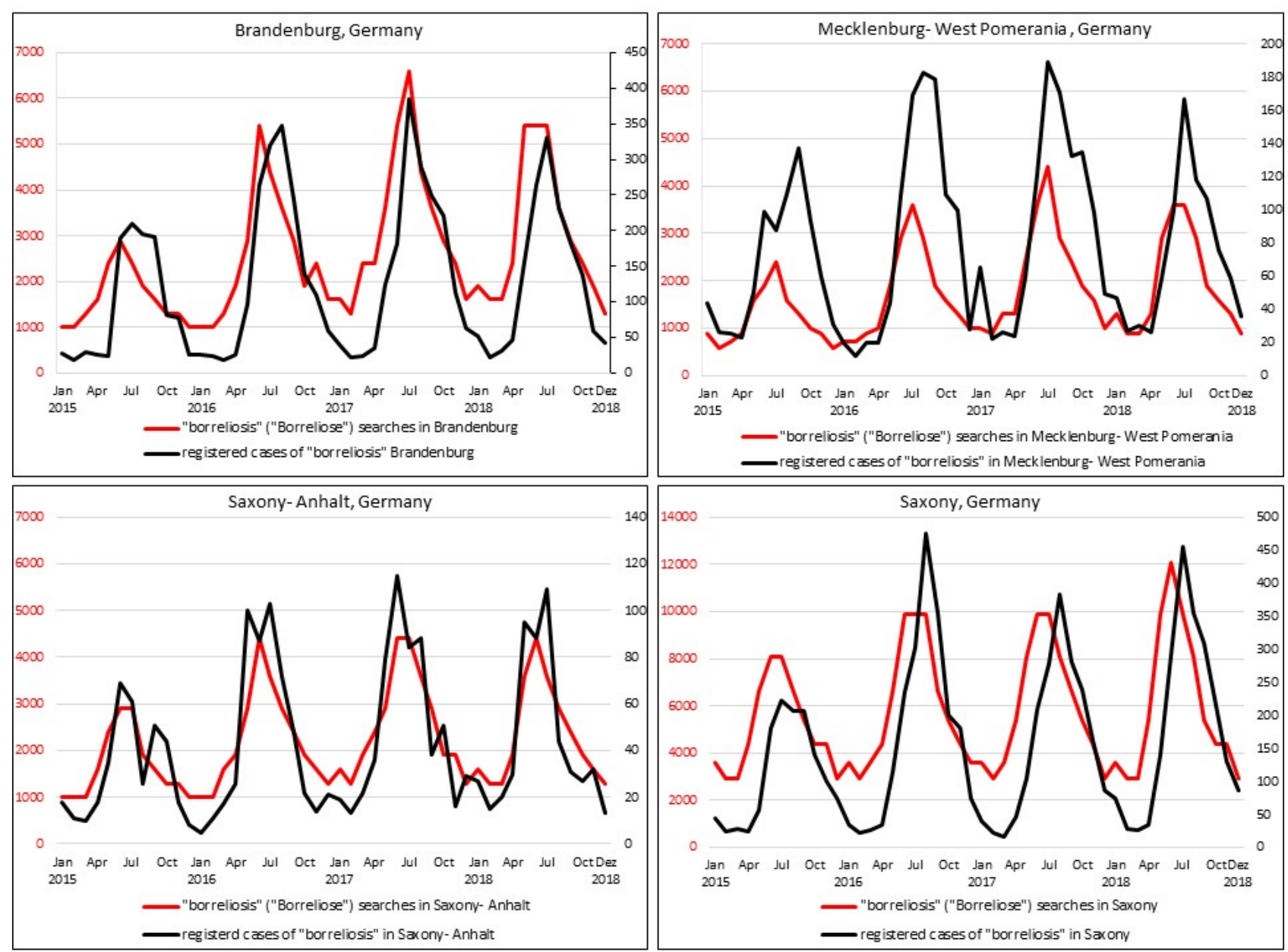

Table 1. Pearson correlation coefficients for Google searches for borreliosis and registered cases of borreliosis from January 2015 to December 2018 in Brandenburg, Mecklenburg-West Pomerania, Saxony, and Saxony-Anhalt.

\begin{tabular}{lllll}
\hline Federal state & Registered cases, $\mathrm{n}$ & Google searches, $\mathrm{n}$ & Pearson correlation & $P$ value \\
\hline Brandenburg & 6107 & 124,000 & 0.80 & 0.77 \\
Mecklenburg-West Pomerania & 3720 & 82,480 & 0.74 & $<.001$ \\
Saxony & 7387 & 273,800 & 0.90 & $<.001$ \\
Saxony-Anhalt & 2016 & 104,700 & $<.001$ \\
\hline
\end{tabular}

\section{Discussion}

\section{Principal Findings}

The analysis of Google search volume related to tick bite and borreliosis identified an annual pattern that people tended to search more frequently during summer months. Therefore, a high correlation with average temperature was observed. Furthermore, a high correlation between registered cases of borreliosis in four German federal states was revealed.

One of the top five key terms of tick bite was borreliosis and vice versa. Therefore, we compared the two most common lay terms, tick bite and borreliosis. Interestingly, the search volume for the latter was higher. Especially in 2017 and 2018, a greater divergence between the keywords was observed, which can be explained by a greater awareness of associated diseases. This might be because of celebrities diagnosed with Lyme disease, such as Bastian Schweinsteiger and Justin Bieber, or because health education programs have taught people to make more accurate searches. Furthermore, media like smartphone apps and video games significantly improve knowledge of the disease and preventive measures $[23,24]$. However, a Finnish survey showed that, regarding knowledge, attitudes, and practice toward ticks and tick-borne disease, $65 \%$ of participants relied on newspapers and magazines as the main source of information [25]. Pharmacy health magazines, radio, or TV shows start media coverage of ticks and tick-borne diseases in late spring when average temperatures rise and ticks begin to appear. 
However, we did not find data to support this well-known approach.

Correlating weather data with the Google search volume showed seasonal trends, which were described in previous works concerning pruritus and identified inhabitants' needs [12]. Especially during the German winter months October 2016 to March 2017 and October 2017 to March 2018, the Google search volume showed a distinctive increase for tick bite and borreliosis compared to data from October 2015 to March 2016. The first hypothesis was that winters get milder in Germany due to climate change so that ticks have a longer active period. Ticks are active when average temperatures are between $4-10{ }^{\circ} \mathrm{C}$ (median $7{ }^{\circ} \mathrm{C}$ ) [19]. However, as during each winter, there were a comparable number of months below this temperature. This does not explain the recognizable increase in search volume that we can see. Potentially, the increase was due to the awareness of tick bites and associated diseases, as well as media campaigns starting earlier in those years.

In some German federal states, it is mandatory to report borreliosis cases. Comparing numbers from Google searches and registered borreliosis cases shows a discrepancy. For example, in Brandenburg, the highest number of registered borreliosis cases in the reviewed years was 1743 in 2017. In comparison, the 2017 Google search volume for "borreliosis" in Brandenburg was 38,200, which is 22 times higher. This might be because the number of tick bites are much greater than the development of borreliosis symptoms. Additionally, not only affected people but also their relatives might search for information online, which explains a considerably higher number of search queries.

Walker [20] posed the question of whether Google trends can be used to study parasitic (ie, tick-borne) diseases [20]. Their results showed seasonal patterns in search volume but no significant correlation between mean monthly temperature and internet searches for "tick." Additionally, they tried to use the internet search volume to estimate parasitic occurrence. However, there was no apparent relationship between the annual number of tick-borne encephalitis cases and mean annual internet searches for either tick or tick-borne encephalitis [20].
We found statistically high correlations between registered borreliosis cases and Google search volume in four federal states. Previous studies identified Google data as a predictor of infectious disease outbreaks [26,27]. Nevertheless, to the best of our knowledge, this is the first work that shows a high correlation between incidence of an infectious disease and Google search volume of the implied disease. These results could help estimate incidences of borreliosis in German federal states where registration is not mandatory. Furthermore, Google search volume could be used to estimate incidences of diseases that are not required to be reported.

\section{Limitations}

This study has some limitations. In Germany, Google accounts for $95 \%$ of search engine use, so Google data can depict the interests of the population as a whole. To transfer our findings to other countries, different market shares of Google over alternative search engines need to be taken into account. Although it is common among the whole population to make health-related searches, younger people tend to use the internet more often [28]. Furthermore, the automatic completion of search terms by Google may influence people's search behavior. It may promote an understanding of the health problem and the need to seek necessary medical help; however, priming by autocomplete has the potential to make incorrect associations [29]. Another limitation to our study is that we solely used German key terms.

\section{Conclusion}

Our study provides insight into terms and fields of interest associated with tick bites and borreliosis, relevant to the German population. We found statistically high correlations between Google searches for borreliosis and registered cases of borreliosis across four German federal states. Accordingly, these results could help to estimate the incidence of borreliosis in the remaining 12 German federal states where it is not mandatory to report borreliosis. Furthermore, this approach could aid in the development and implementation of effective and sustainable awareness campaigns.

\section{Acknowledgments}

This work was supported by the department of Dermatology and Allergy, Technical University of Munich, School of Medicine, Munich, Germany.

\section{Conflicts of Interest}

None declared.

\section{References}

1. Glatz M, Resinger A, Semmelweis K, Ambros-Rudolph C, Müllegger RR. Clinical spectrum of skin manifestations of Lyme borreliosis in 204 children in Austria. Acta Derm Venereol 2015 May;95(5):565-571 [FREE Full text] [doi: 10.2340/00015555-2000] [Medline: 25366035]

2. Huppertz HI, Böhme M, Standaert SM, Karch H, Plotkin SA. Incidence of Lyme borreliosis in the Würzburg region of Germany. Eur J Clin Microbiol Infect Dis 1999 Oct;18(10):697-703. [doi: 10.1007/s100960050381] [Medline: 10584895]

3. Hofmann H, Fingerle V, Hunfeld KP, Huppertz HI, Krause A, Rauer S, Consensus group. Cutaneous Lyme borreliosis: guideline of the German Dermatology Society. Ger Med Sci 2017;15:Doc14. [doi: 10.3205/000255] [Medline: 28943834] 
4. Enkelmann J, Böhmer M, Fingerle V, Siffczyk C, Werber D, Littmann M, et al. Incidence of notified Lyme borreliosis in Germany, 2013-2017. Sci Rep 2018 Oct 08;8(1):14976. [doi: 10.1038/s41598-018-33136-0] [Medline: 30297731]

5. Welche Suchmaschinen haben Sie in den letzten 4 Wochen genutzt? Statista. URL: https://de.statista.com/prognosen/ 999767/umfrage-in-deutschland-zu-beliebten-suchmaschinen [accessed 2019-06-25]

6. Mazloomdoost D, Kanter G, Chan RC, Deveaneau N, Wyman AM, Von Bargen EC, et al. Social networking and internet use among pelvic floor patients: a multicenter survey. Am J Obstet Gynecol 2016 Nov;215(5):654.e1-654.e10. [doi: 10.1016/j.ajog.2016.06.011] [Medline: 27319368]

7. Lee K, Hoti K, Hughes JD, Emmerton L. Dr Google is here to stay but health care professionals are still valued: an analysis of health care consumers' internet navigation support preferences. J Med Internet Res 2017 Jun 14;19(6):e210 [FREE Full text] [doi: 10.2196/jmir.7489] [Medline: 28615156]

8. Eysenbach G, Köhler C. How do consumers search for and appraise health information on the world wide web? Qualitative study using focus groups, usability tests, and in-depth interviews. BMJ 2002 Mar 09;324(7337):573-577 [FREE Full text] [doi: 10.1136/bmj.324.7337.573] [Medline: 11884321]

9. Sharpe JD, Hopkins RS, Cook RL, Striley CW. Evaluating Google, Twitter, and Wikipedia as tools for influenza surveillance using Bayesian change point analysis: a comparative analysis. JMIR Public Health Surveill 2016 Oct 20;2(2):e161 [FREE Full text] [doi: 10.2196/publichealth.5901] [Medline: 27765731]

10. Seidl S, Schuster B, Rüth M, Biedermann T, Zink A. What do Germans want to know about skin cancer? A nationwide Google search analysis from 2013 to 2017. J Med Internet Res 2018 May 02;20(5):e10327 [FREE Full text] [doi: 10.2196/10327] [Medline: 29698213]

11. Zink A, Schuster B, Rüth M, Pereira M, Philipp-Dormston WG, Biedermann T, et al. Medical needs and major complaints related to pruritus in Germany: a 4-year retrospective analysis using Google AdWords Keyword Planner. J Eur Acad Dermatol Venereol 2019 Jan;33(1):151-156. [doi: 10.1111/jdv.15200] [Medline: $\underline{30067284]}$

12. Tizek L, Schielein M, Rüth M, Ständer S, Pereira MP, Eberlein B, et al. Influence of climate on Google internet searches for pruritus across 16 German cities: retrospective analysis. J Med Internet Res 2019 Jul 12;21(7):e13739 [FREE Full text] [doi: 10.2196/13739] [Medline: 31301128]

13. Amante DJ, Hogan TP, Pagoto SL, English TM, Lapane KL. Access to care and use of the Internet to search for health information: results from the US National Health Interview Survey. J Med Internet Res 2015 Apr 29;17(4):e106 [FREE Full text] [doi: 10.2196/jmir.4126] [Medline: 25925943]

14. Mavragani A. Infodemiology and infoveillance: scoping review. J Med Internet Res 2020 Apr 28;22(4):e16206 [FREE Full text] [doi: 10.2196/16206] [Medline: 32310818]

15. Eysenbach G. Infodemiology and infoveillance: framework for an emerging set of public health informatics methods to analyze search, communication and publication behavior on the Internet. J Med Internet Res 2009 Mar 27;11(1):e11 [FREE Full text] [doi: 10.2196/jmir.1157] [Medline: 19329408]

16. Huang X, Baade P, Youlden DR, Youl PH, Hu W, Kimlin MG. Google as a cancer control tool in Queensland. BMC Cancer 2017 Dec 04;17(1):816 [FREE Full text] [doi: 10.1186/s12885-017-3828-x] [Medline: 29202718]

17. Wehner MR, Nead KT, Linos E. Correlation among cancer incidence and mortality rates and internet searches in the United States. JAMA Dermatol 2017 Sep 01;153(9):911-914 [FREE Full text] [doi: 10.1001/jamadermatol.2017.1870] [Medline: 28658470]

18. Ginsberg J, Mohebbi MH, Patel RS, Brammer L, Smolinski MS, Brilliant L. Detecting influenza epidemics using search engine query data. Nature 2009 Mar 19;457(7232):1012-1014. [doi: 10.1038/nature07634] [Medline: 19020500]

19. Bouchard C, Dibernardo A, Koffi J, Wood H, Leighton P, Lindsay L. N Increased risk of tick-borne diseases with climate and environmental changes. Can Commun Dis Rep 2019 Apr 04;45(4):83-89. [doi: 10.14745/ccdr.v45i04a02] [Medline: 31285697]

20. Walker M. Can Google be used to study parasitic disease? Internet searching on tick-borne encephalitis in Germany. J Vector Borne Dis 2018;55(4):327-329 [FREE Full text] [doi: 10.4103/0972-9062.256571] [Medline: $\underline{30997896]}$

21. Wetterdienst D. Offenbach, Germany: Deutscher Wetterdienst Climate Data Center. URL: https://www.dwd.de/DE/ leistungen/klimadatendeutschland/klarchivtagmonat.html?nn=480164 [accessed 2019-05-01]

22. Mukaka M. Statistics corner: a guide to appropriate use of correlation coefficient in medical research. Malawi Med J 2012;24(3):69-71.

23. Antonise-Kamp L, Beaujean DJMA, Crutzen R, van Steenbergen JE, Ruwaard D. Prevention of tick bites: an evaluation of a smartphone app. BMC Infect Dis 2017 Dec 04;17(1):744 [FREE Full text] [doi: 10.1186/s12879-017-2836-4] [Medline: 29202704]

24. Beaujean DJMA, Gassner F, Wong A, Steenbergen JE, Crutzen R, Ruwaard D. Education on tick bite and Lyme borreliosis prevention, aimed at schoolchildren in the Netherlands: comparing the effects of an online educational video game versus a leaflet or no intervention. BMC Public Health 2016 Nov 16;16(1):1163 [FREE Full text] [doi: 10.1186/s12889-016-3811-5] [Medline: 27852247]

25. Zöldi V, Turunen T, Lyytikäinen O, Sane J. Knowledge, attitudes, and practices regarding ticks and tick-borne diseases, Finland. Ticks Tick Borne Dis 2017 Oct;8(6):872-877. [doi: 10.1016/j.ttbdis.2017.07.004] [Medline: 28778675] 
26. Simonsen L, Gog JR, Olson D, Viboud C. Infectious disease surveillance in the big data era: towards faster and locally relevant systems. J Infect Dis 2016 Dec 01;214(suppl_4):S380-S385 [FREE Full text] [doi: 10.1093/infdis/jiw376] [Medline: 28830112]

27. Verma M, Kishore K, Kumar M, Sondh AR, Aggarwal G, Kathirvel S. Google search trends predicting disease outbreaks: an analysis from India. Healthc Inform Res 2018 Oct;24(4):300-308 [FREE Full text] [doi: 10.4258/hir.2018.24.4.300] [Medline: $\underline{30443418]}$

28. Ybarra ML, Suman M. Help seeking behavior and the Internet: a national survey. Int J Med Inform 2006 Jan;75(1):29-41. [doi: 10.1016/j.ijmedinf.2005.07.029] [Medline: 16129659]

29. Loh LC. Autocomplete: Dr Google's "helpful" assistant? Can Fam Physician 2016 Aug;62(8):622-623. [Medline: 27521382]

Edited by G Eysenbach; submitted 05.03.20; peer-reviewed by S Salzmann, C Liao; comments to author 20.04.20; revised version received 06.05.20; accepted 20.05.20; published 16.10.20

Please cite as:

Scheerer C, Rüth M, Tizek L, Köberle M, Biedermann T, Zink A

Googling for Ticks and Borreliosis in Germany: Nationwide Google Search Analysis From 2015 to 2018

J Med Internet Res 2020;22(10):e18581

URL: http://www.jmir.org/2020/10/e18581/

doi: $10.2196 / 18581$

PMID: 33064086

(C) Cora Scheerer, Melvin Rüth, Linda Tizek, Martin Köberle, Tilo Biedermann, Alexander Zink. Originally published in the Journal of Medical Internet Research (http://www.jmir.org), 16.10.2020. This is an open-access article distributed under the terms of the Creative Commons Attribution License (https://creativecommons.org/licenses/by/4.0/), which permits unrestricted use, distribution, and reproduction in any medium, provided the original work, first published in the Journal of Medical Internet Research, is properly cited. The complete bibliographic information, a link to the original publication on http://www.jmir.org/, as well as this copyright and license information must be included. 